\title{
Karakteristika ved to territorier for hvitryggspett Dendrocopos leucotos i Telemark
}

\author{
Arne Heggland
}

Heggland,A. 2004. Karakteristika ved to territorier for hvitryggspett Dendrocopos leucotos i Telemark. - Ornis Norvegica 27: 80-85.

I investigated two territories of the White-backed Woodpecker Dendrocopos leucotos situated in Skien and Notodden (Telemark). The territories are situated in the far east in the range of the Norwegian Sørlandet population. One territory (Notodden) was situated in a stand of grey alder. The amount of fallen and standing dead trees was investigated using two census plots. The density of fallen and standing dead trees (mostly grey alder) was 324 and 137 truncs/ha, respectively. A well defined area covering 33 ha of high quality foraging habitats represents an estimate of the home range during the nestling period. The other territory (Skien) was situated in a landscape where decidous forests are heavily fragmented. All suitable foraging habitats (stands of decidous forest with high density of dead and dying trees) were mapped within the area $0-3 \mathrm{~km}$ from the nesting site (a circular area of $28 \mathrm{~km}^{2}$ ). Patches of decidous forests occurs as 1-10 ha patches in a matrix of clearcuts and young stands of spruce. Decidous forest makes up only $4 \%$ of the total area. The area within $1 \mathrm{~km}$ from the nest site showed the greatest abundance of suitable foraging habitats (480 ha, 15,4\% of the total area), while the density of suitable foraging habitats declined further away from the nest site. Changes in forest structure leading to reduced amount of suitable foraging habitats on a landscape level is believed to be the main reason for the decline in the population of the White-backed Woodpecker in eastern parts of Norway, as well as in Western Europe as a whole.

Arne Heggland, Ekornveien 5, 4818 Farvik.E-post: arne@sistesjanse.no

\section{INNLEDNING}

Et hekketerritorium for hvitryggspett i Notodden (Telemark) ble undersøkt. I tillegg presenteres data fra et leveområdet for arten i et sterkt fragmentert skoglandskap i Skien i nedre Telemark. Dette er de første undersøkelsene av hekketerritorier for hvitryggspett i Telemark, og det eksisterer lite dokumentasjon av skogstruktur og arealbruk i hvitryggspettens leveområder på $\varnothing$ stlandet for $\varnothing$ vrig. Hvitryggspetten er rødlistet som sårbar (Direktoratet for naturforvaltning 1999), og Telemark utgjør sammen med AustAgder en overgangssone der arten går fra å være jevnt utbredt (Vest-Agder) til å være nærmest forsvunnet som hekkefugl (Vestfold, Buskerud og Øvrige Østlandsfylker, se Stenberg 1998). Kunnskap om arten, dens leveområder og bestandsutvikling i Telemark er derfor viktig i forvaltningsøyemed.

\section{MATERIALE OG METODE}

Artikkelen baserer seg på feltarbeid 15.-16.5, 4.6.2002 samt oktober 2000 (Notodden) og ekstensivt feltarbeid i perioden 1998-2002 (Skien). Notodden-lokaliteten ligger nordøst i Telemark, ca $59^{\circ} 50^{\prime} \mathrm{N} / 9^{\circ} \mathrm{E}$ og spenner fra 200 til 400 m.o.h. To kvadratiske prøveflater ble benyttet for registrering av dødt trevirke på denne lokaliteten; én 0,16 ha flate ved hvitryggspettreiret i 2002 og én 0,25 ha flate ca $750 \mathrm{~m}$. fra reirtreet. All død ved med diameter $>10 \mathrm{~cm}$ (basismål for liggende død ved (læger), brysthøydemål for stående død ved (gadd)) ble talt opp og følgende parametre bestemt: Treslag, type (liggende død ved (læger), hel gadd (=stående dødt tre uten brudd på hovedstamme), høgstubbe (1-6 m) eller kort stubbe $(<1 \mathrm{~m}))$, nedbrytningsgrad, basistykkelse (10 $\mathrm{cm}$ intervaller) og hvorvidt det var ferske dyphakkemerker etter hvitryggspett 
(gjelder kun flata ved reiret). Nedbrytningsgraden for gadd og læger ble kategorisert fra 1 til 5: 1 (fersk; ingen synlig råte), 2 (0 til $3 \mathrm{~cm}$ råte), 3 (3 cm råte til gjennområtten), 4 (gjennområtten, stokken følger i hovedsak underlaget) og 5 (ingen fast substans). Artsbestemmelse av hakkemerker baserer seg på tidligere erfaring og er nær $100 \%$ sikker. Vurdering av alder for hakkemerker er subjektiv, og med ferske hakkemerker menes i denne sammenheng årsferske merker, der veden ennå er lys og frisk.

Skienslokaliteten ligger i nedre Telemark, ca. $5^{\circ} 24^{\prime} \mathrm{N} / 9^{\circ} 30^{\prime} \mathrm{E}$ og spenner fra 290 til 550 m.o.h. Et territorium for hvitryggspett ble identifisert på bakgrunn av to reirfunn med ca $200 \mathrm{~m}$ avstand (1998 og 1999). All eldre løvskog i radius ca 0-3 km ut fra hekkelokaliteten ble identifisert og tegnet inn på kart.

\section{RESULTATER}

Hvitryggspett-reiret i Notodden ligger sentralt i et 33 ha stort areal med løvskog som er innrammet og avgrenset av en stor innsjø, bratte partier med bart fjell og områder med granskog med lite dødt trevirke (Fig. 1). Observasjoner av fuglene og vurdering av nærliggende habitat tilsier at fuglene benytter dette området ved næringss $\varnothing \mathrm{k}$ til ungefôring, og arealet på 33 ha er her betraktet som parets leveområdet i ungenes reirperiode (se diskusjon). Dominerende vegetasjonstyper er lavurtgranskog og gråor-heggeskog. Gråor dominerer i tresjiktet. I tillegg forekommer hegg, bjørk, gran, osp (alle vanlig), selje, rogn, alm, lind, lønn og hassel (spredt). Prøveflatene inneholder til sammen 133 læger (324 læger/ha), hvorav gråor (77 læger) dominerer og bartrær (gran) bare utgjør $20 \%$. Det er dominans av råtestadium 2 og 3 (31\% hver), se tabell 1 . I alt 27 av lægerne (20\%) har basisdiameter $>20$ $\mathrm{cm}$, og av disse er bare 8 løvtrær. Totalt 56 gadd ble talt opp i prøveflatene (tetthet $137 \mathrm{gadd} / \mathrm{ha}$ ), hvorav gråor dominerer (66 \%) og bartrær (gran) bare utgjør $11 \%$. Av gadd er $46 \%$ høgstubber, alle løvtrær. Nedbrytningsstadium 3 dominerer for gadd (43\%, kun data fra 1 prøveflate), se tabell 1. Tettheten av læger og gadd er h.h.v. 1,8 og 4,6 ganger høyere ved reiret enn i den perifere flata. Dersom vi ekskluderer bartrær, blir de tilsvarende forholdstallene h.h.v. 5,7 og 8,2. Av 84 unders $\varnothing$ kte læger, hadde 15 (18\%) ferske dyphakkemerker, hvorav 14 gråor. Det ble det funnet dyphakkemerker i 13 av 41 unders $\varnothing$ kte gadd (32\%), og 12 av disse var gadd av gråor.

Reirlokaliteten i Skien ligger i sentrum av et skogområde hvor gammel løvskog finnes i 1ca. 10 ha store flekker (Fig. 2), og hvor store granplantefelt for $\varnothing v$ rig dominerer skogbildet. I sirkelen med radius $1 \mathrm{~km}$ ut fra reiret finnes det 5
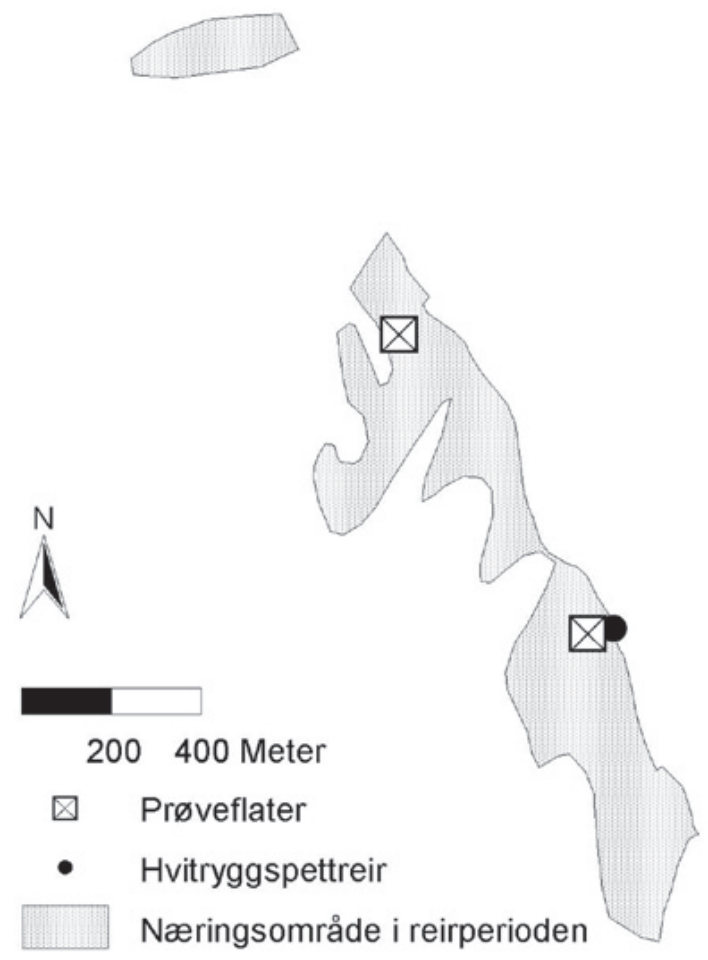

Figur 1. Form på leveområde for hvitryggspett ved hekkelokalitet i Notodden/Telemark våren 2002. For definisjon av leveområde se tekst.

Shape of the foraging habitat surrounding a nesting locality of the White-backed Woodpecker in Notodden/ Telemark. 
Tabell 1. Antall dфde traer i to prфveflater på hekkeplass for hvitryggspett i Notodden.

Number of dead trees within two census plots in a territorium of the White-backed Woodpekcer, Notodden, Telemark.

$\begin{array}{ccc}\text { Sentral flate (central plot }) & \begin{array}{c}\text { Perifer flate (peripheral } \\ (0,16 \mathrm{ha})\end{array} & \text { plot })(0,25 \mathrm{ha})\end{array}$

\begin{tabular}{|c|c|c|c|c|c|c|c|c|c|c|c|c|c|c|c|c|c|c|c|}
\hline & Decay $\rightarrow$ & 1 & 2 & 3 & 4 & 5 & $1-5$ & 1 & 2 & 3 & 4 & 5 & $1-5$ & 1 & 2 & 3 & 4 & 5 & $1-5$ \\
\hline Læger & Bjørk & & 1 & 7 & & 6 & 14 & & & 3 & 4 & 1 & 8 & & 1 & 10 & 4 & 7 & 22 \\
\hline Fallen & Gran & & & & & & & & 12 & 7 & 5 & 2 & 26 & & 12 & 7 & 5 & 2 & 26 \\
\hline \multirow[t]{4}{*}{ truncs } & Gråor & & 21 & 19 & 15 & 13 & 68 & & 3 & 4 & 1 & 1 & 9 & & 24 & 23 & 16 & 14 & 77 \\
\hline & Lind & & 1 & & & & 1 & & 1 & & & & 1 & & 2 & & & & 2 \\
\hline & Rogn & & & & & 1 & 1 & 1 & & & & & 1 & 1 & & & & 1 & 2 \\
\hline & Selje & & & & & & & & 2 & 1 & & 1 & 4 & & 2 & 1 & & 1 & 4 \\
\hline \multicolumn{2}{|c|}{ Totalt (total) } & & 23 & 26 & 15 & 20 & 84 & 1 & 18 & 15 & 10 & 5 & 49 & 1 & 41 & 41 & 25 & 25 & 133 \\
\hline Gadd & Bjørk & 1 & 2 & 1 & & & 4 & & & & & & 4 & & & & & & 8 \\
\hline Standing & Gran & 1 & & & & & 1 & & & & & & 6 & & & & & & 7 \\
\hline \multirow[t]{4}{*}{ dead trees } & Gråor & & 10 & 17 & 8 & 1 & 36 & & & & & & 1 & & & & & & 37 \\
\hline & Osp & & & & & & & & & & & & 1 & & & & & & 1 \\
\hline & Rogn & & & & & & & & & & & & 1 & & & & & & 1 \\
\hline & Selje & & 1 & & & & 1 & & & & & & 1 & & & & & & 2 \\
\hline \multicolumn{2}{|c|}{ Totalt (total) } & 2 & 13 & 18 & 8 & 1 & 42 & & & & & & 14 & & & & & & 56 \\
\hline
\end{tabular}

løvskogsflekker med et totalareal på 48 ha $(15,4$ $\%$ av alt areal i sirkelen). Arealet i sirkelskiva med avstand 1-2 km ut fra reiret har 8 flekker med gammel løvskog, totalt 32 ha $(3,4 \%$ av alt areal i sirkelen). Tilsvarende tall for sirkelskiva 2-3 km fra reiret er 7 flekker og 30 ha $(1,9 \%)$. Samlet mengde løvrike skoger i avstand 0 til 3 $\mathrm{km}$ ut fra reiret er 111 ha (4\% av totalt areal), hvorav $44 \%$ ligger i den innerste sirkelen (0-1 $\mathrm{km}$ fra reirområdet). Den benyttede reirplassen ligger sentralt i den klart mest løvrike delen av det unders $\varnothing$ kte området på $28 \mathrm{~km}^{2}$. Dersom en forenklet forestiller seg territoriet som en sirkelrund skive med radius $1 \mathrm{~km}$, og flytter sentrum for et tenkt territorium h.h.v. 1 og $2 \mathrm{~km}$ ut fra den observerte reirplassen, vil de antatt beste territoriene (d.v.s. mest areal løvskog 82 innen sirkelen) inneholde h.h.v. ca 25 ha og 33 ha løvskog, d.v.s. atskillig mindre enn observert på den benyttede hekkeplassen.

\section{DISKUSJON}

På begge lokalitetene ble reiret plassert i en del av området med særlig mye dødt trevirke. Fordelingen av løvrike skogtyper i et større område rundt hekkeplassen i Skien (figur 2 og resultater) viser at det neppe finnes mange alternative plasseringer av hekketerritoriet på denne lokaliteten - noe gjentatte hekkinger $\mathrm{i}$ et lite delområde synes å bekrefte. Det finnes få undersøkelser som peker på hvor stort område hvitryggspetten bruker i ungens reirperiode, 


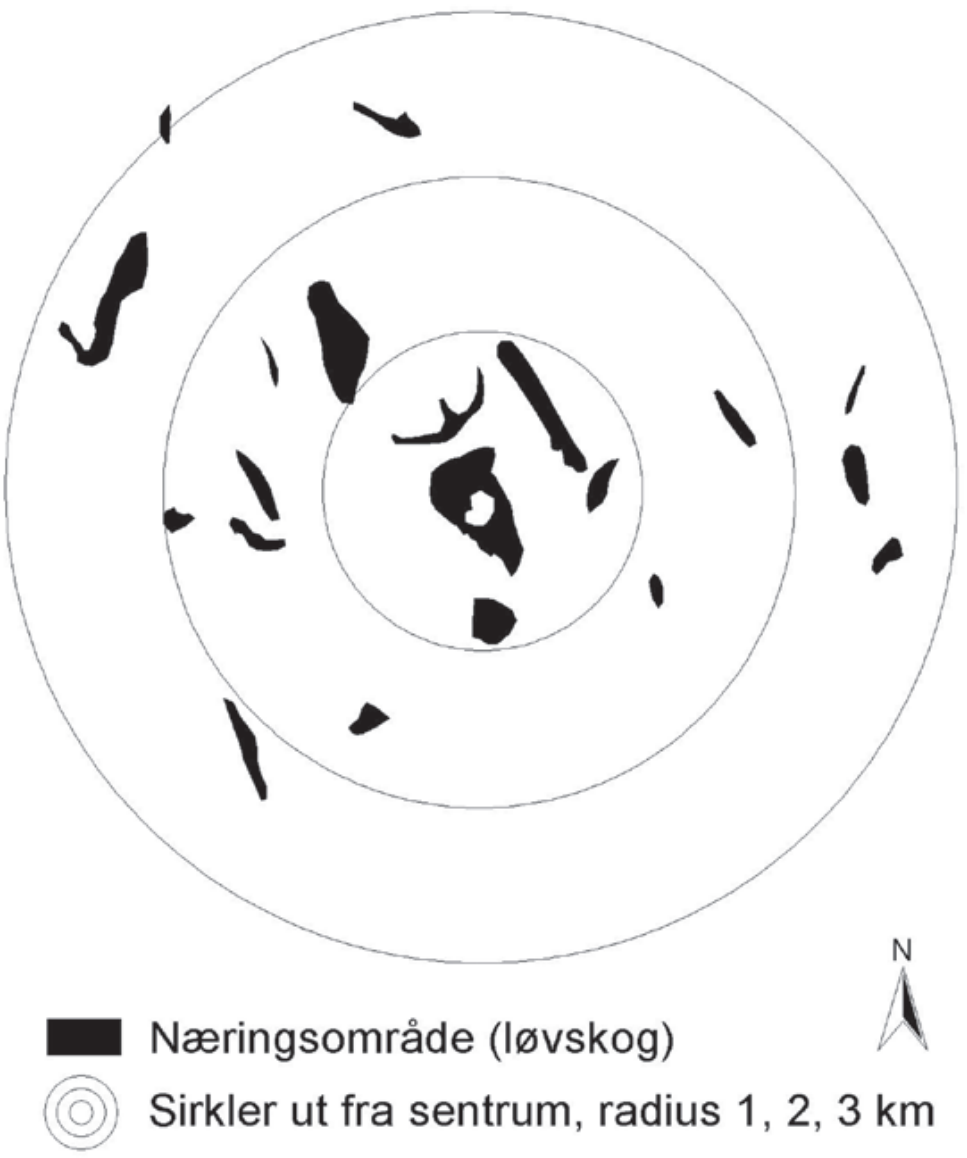

Figur 2. Fordeling av egnet naringshabitat for hvitryggspett på reirlokalitet $i$ Skien. Benyttet reirplass ligger $i$ sentrum av figuren.

Distribution of suitable foraging habitats for White-backed Woodpecker on a locality in Skien/Telemark.

men arten er en god flyger og en må regne med at foreldrefuglene kan bevege seg $>1 \mathrm{~km}$ (jfr. f.eks. Pynnönen (1939)) for å hakke fram mat til ungene. Fødes $\varnothing \mathrm{k}$ utenfor det definerte leveområdet på 33 ha på Notodden-lokaliteten betyr lange flygeturer mellom hver fôring ( $>2500$ meter hver vei, mye gjennom åpent terreng), noe som både ville være energikrevende og ugunstig m.h.p. predasjonsrisiko. Det er derfor rimelig å anta at fuglene unngår slike flygeturer, og at området på 33 ha ved reiret kan være et stort nok næringsområde for hvitryggspettparet i ungenes reirperiode. På Skienslokaliteten er ikke leveområdet så godt innrammet som på Notodden-lokaliteten. Dersom en antar at hekketerritoriet befinner seg innenfor en sirkel med radius $1 \mathrm{~km}$ fra reirtreet, betyr det at tilgjengelig næringshabitat $\mathrm{i}$ ungenes reirperiode på Skienslokaliteten er 48 ha.

En undersøkelse fra Vestfold (Bringeland \& Fjære 1981) peker på at de voksne hvitryggspettene ut fra hyppig matingsfrekvens og direkte observasjon etter alt å dømme hovedsakelig søkte føde i områder relativt nær reiret i ungenes reirperiode. På Vestlandet er det funnet at området umiddelbart rundt hvitryggspettens reirtre er spesielt rik på dødt trevirke (Hogstad 
\& Stenberg 1994), og at høy matingsfrekvens indikerer fødes $\varnothing \mathrm{k}$ i den umiddelbare nærheten av reiret (kanskje i radius $200-500$ meter ut fra reirtreet). Mine observasjoner fra de to Telemarks-lokalitetene stemmer godt over ens med disse referansene.

Unders $\varnothing$ kelser har vist at størrelsen på samlet sommer- og vinterterritorium for et etablert hvitryggspettpar ligger i størrelsesorden 75-200 haa (Bringeland \& Fjære 1981, Aulén 1988). For begge de to Telemarkslokalitetene må en derfor anta at parets totale territorium gjennom året trolig er supplert med arealer utenfor de $33 \mathrm{og}$ 48 ha som inngår i mitt estimat av leveområde i reirperioden. Hogstad \& Stenberg (1997) rapporterer at de voksne fuglene gjennom vinteren ofte observeres i hekketerritoriet. Det energimessig optimale er at fuglenes helårs leveområde er samlet i én stor flekk med egnet habitat. På mange av de antatt beste lokalitetene for arten i Telemark, og for Øvrig på Østlandet, har hogst redusert og fragmentert andelen gammel løvskog kraftig. Bildet av en flekkvis fordeling av egnet nærings-habitat som framkommer av figur 2 er trolig representativt for mange tidligere hekkelokaliteter for arten på Østlandet. Slike lokaliteter kan inneholde restområder av høy kvalitet for hvitryggspett.

Unders $ø$ kelser av hvitryggspettens leveområder i Norge peker på den høye andelen døde trær i territoriet (Gjerde et al. 1992; Hogstad \& Stenberg 1994; Stenberg \& Stokke 2003). Hogstad \& Stenberg (1994) kvantifiserte gjennomsnittlig antall døde trær i 29 reirområder for hvitryggspett i Møre og Romsdal til 154 gadd/ha og 195 120 læger eller døende, liggende trær/ha. En tilsvarende unders $\varnothing$ kelse fra Sørlandet gav 183 gadd/ha og 267 125 læger/haa (Stenberg \& Stokke 2003). Egne data kan ikke uten videre sammenliknes med dataene fra Møre og Romsdal og Sørlandet, i det metoden ikke er identisk (den viktigste forskjellen er at førstnevnte studier inkluderer $\mathrm{d} ø \mathrm{~d}$ ved med minste diameter mål ned til $5 \mathrm{~cm}$, mot $10 \mathrm{~cm}$ i dette arbeidet). Tatt i betraktning at jeg har ekskludert stammer $<10$ $\mathrm{cm}$ på Notodden-lokaliteten, synes tettheten av død ved på denne lokaliteten (324 læger/ha og 136 gadd/ha) å være temmelig høy. Lokalt god fødetilgang kan kanskje forklare at fuglene gjennomførte hekking, til tross for at tilgjengelig areal bare var 33 ha.

Totalt 28 av de 125 unders $\varnothing$ kte elementene (liggende og stående død ved) på Notoddenlokaliteten (22\%) hadde ferske dyphakkemerker av hvitryggspett, og prosentvis var det flere gadd (32\%) enn læger (18\%) med hakkemerker. Hvitryggspetten søker føde både på liggende og stående dødt virke (Aulén 1988, Hogstad \& Stenberg 1994), og i snørike områder (gjelder både Notodden og Skien) er forekomst av stående dødt virke essensielt vinterstid. Bare dyphakkemerker ble notert i min unders $ø$ kelse, og metoden er uegnet til å estimere antallet elementer som fuglene har søkt føde i fordi selv hannen (som i større grad enn hunnen benytter dyphakking) bruker andre teknikker enn dyphakking i opp i mot 50\% av tilfellene (Stenberg 1998). 26 av 28 elementer med hakkemerker var gråor, som forventet ut fra den store forekomsten av død gråor på lokaliteten. For både læger og gadd er det en overvekt av hakkemerker i død ved i nedbrytningsstadium 3, som antydet ut fra forekomsten (se tabell 1). Gråorskoger langs vann og vassdrag er en kjent type leveområde for hvitryggspett (se f.eks. Gjerde et al. (1992)). Gråorskog når etter bare 30-40 år en fase med mye død ved. Mulige hekkelokaliteter for hvitryggspett i gråorskog har følgelig en rask leveringstid m.h.p. restaurering.

Reirfunnet fra Notodden er særlig interessant fordi det ligger langt nordøst i utbredelsesområdet til den sørnorske populasjonen. I bygdene omkring reirlokaliteten finnes store konsentrasjoner av løvskog langs vassdrag, i tilknytning til halvåpent og gjenvokst kulturlandskap og ellers i næringsrike og/eller varme lisider. Ferske inventeringer viser at hvityggspett forekommer på flere lokaliteter i denne delen av Telemark (Heggland 2004). 
Sett i lys av den svake bestanden i nedre Telemark, er det lite trolig at kystnære områder i fylket produserer et overskudd som kan supplere fugl til indre deler av fylket. Muligens kan bestanden av hvitryggspett langs Telemarksvassdragene være en mer eller mindre levedyktig rest av en tidligere sammenhengende bestand på Sør- og Østlandet. Alternativt kan løvrike lokaliteter og korridorer langs vassdragene i vest- og midtTelemark være en viktig spredningsvei østover for streifende hvitryggspetter fra Sør- og Sørvestlandspopulasjonen.

Takk til Ingvar Stenberg for kommentarer.

\section{REFERANSER}

Aulén, G. 1988. Ecology and distribution of the Whitebacked woodpecker Dendrocopus leucotos in Sweden. Rapport 14. Institutionen för viltekologi, Sveriges Lantbruksuniversitet, Uppsala.

Bringeland, R. \& Fjære, T. 1981. Trekk fra hekkebiologien hos hvitryggspett Dendrocopos leucotos i Norge. - Fauna Norvegica, Ser C,
Cinclus 4: 40-46.

Direktoratet for Naturforvaltning 1999. Nasjonal rødliste for truete arter i Norge 1998. $D N$ rapport 1999-3.

Gjerde, I., Rolstad, J. \& Rinden, H. 1992. Hvitryggspetten på Østlandet: Hekkehabitat og bestandsutvikling sett i forhold til driftsendringer i landbruket. Rapp. Skogforsk 199215. Rapport 4 fra forskning sprogrammet «Skog $\phi$ kologi og flersidig skogbruk».

Heggland, A. 2004. Hvitryggspett i Telemark: Resultat av inventeringer i Tinnsjø- og Bandakområdet 2003 samt oppdatert bestandsstatus. NOF-Telemark rapport $2004-1$.

Hogstad, O. \& Stenberg, I. 1994. Habitat selection of a viable population of White-backed Woodpeckers Dendrocopos leucotos. - Fauna norv. Ser. C, Cinclus 17: 75-94.

Hogstad, O. \& Stenberg, I. 1997. Breeding success, nestling diet and parental care in the Whitebacked Woodpecker (Dendrocopos leucotos). - Journal für Ornithologie 138: 25-38.

Pynnönen, A. 1939. Beiträge zur kenntnis der Biologie finnischer Spechte. - Ann. Zool. Soc.-Bot. Fenn. «Vanamo» 7: 1-172.

Stenberg, I. 1998. Habitat selection, reproduction and survival in the White-backed Woodpecker Dendrocopos leucotos. Dr. Scient. thesis, NTNU Trondheim.

Stenberg, I. \& Stokke, P.K. 2003. Kvitryggspettens habitatval i Noreg. NOF Rapportserie $n r$. 2-2003. Norsk Ornitologisk Forening, Trondheim. 